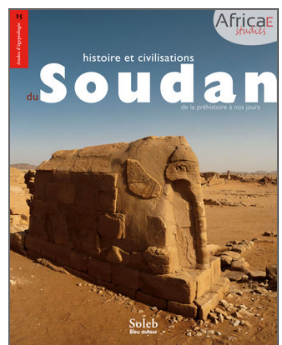

Olivier Cabon (dir.)

Histoire et civilisation du Soudan

De la préhistoire à nos jours

\title{
La nourriture
}

\section{Odile Nicoloso et Nicolas Beaumé}

DOI : 10.4000/books.africae. 2987

Éditeur : Africae, Soleb, Bleu autour

Lieu d'édition : Paris, Khartoum

Année d'édition : 2017

Date de mise en ligne : 17 janvier 2022

Collection : Africae Studies

EAN électronique : 9782493207074

\section{OpenEdition}

\section{Books}

http://books.openedition.org

\section{Référence électronique}

NICOLOSO, Odile ; BEAUMÉ, Nicolas. La nourriture In : Histoire et civilisation du Soudan : De la préhistoire à nos jours [en ligne]. Paris, Khartoum : Africae, 2017 (généré le 28 janvier 2022). Disponible sur Internet : <http://books.openedition.org/africae/2987>. ISBN : 9782493207074. DOI : https://doi.org/ 10.4000/books.africae.2987. 

i.

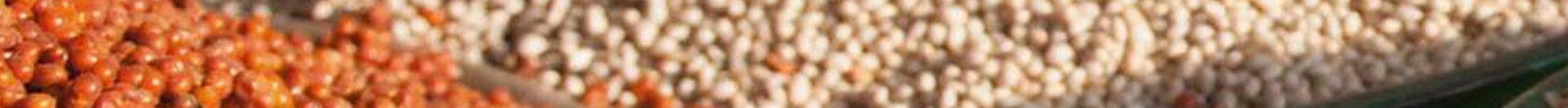

SW

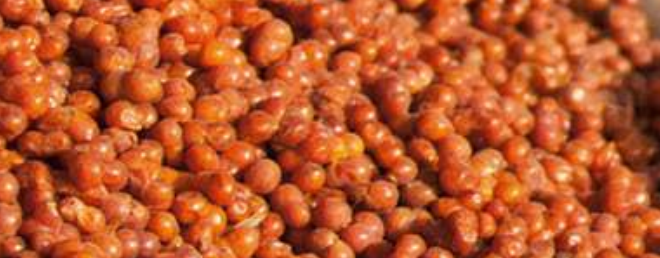

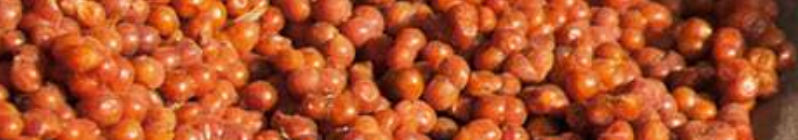

\section{$\cos _{2} \mathrm{~s}, \mathrm{~s}$

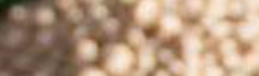 \\ rosigen}

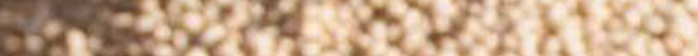

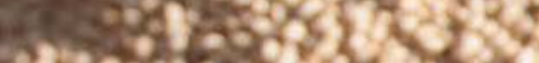

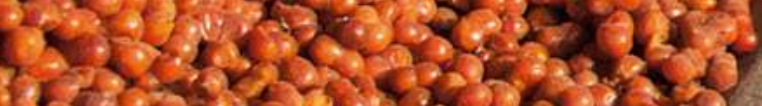

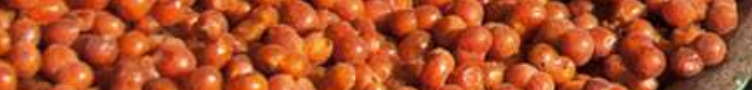

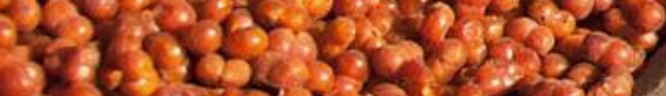

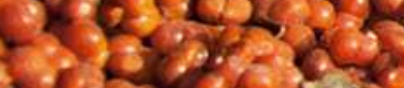

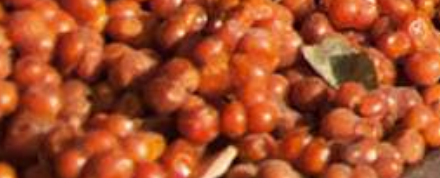

23.

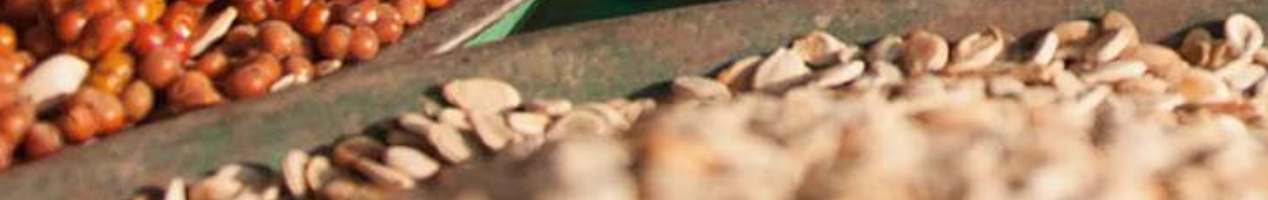

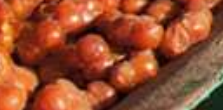



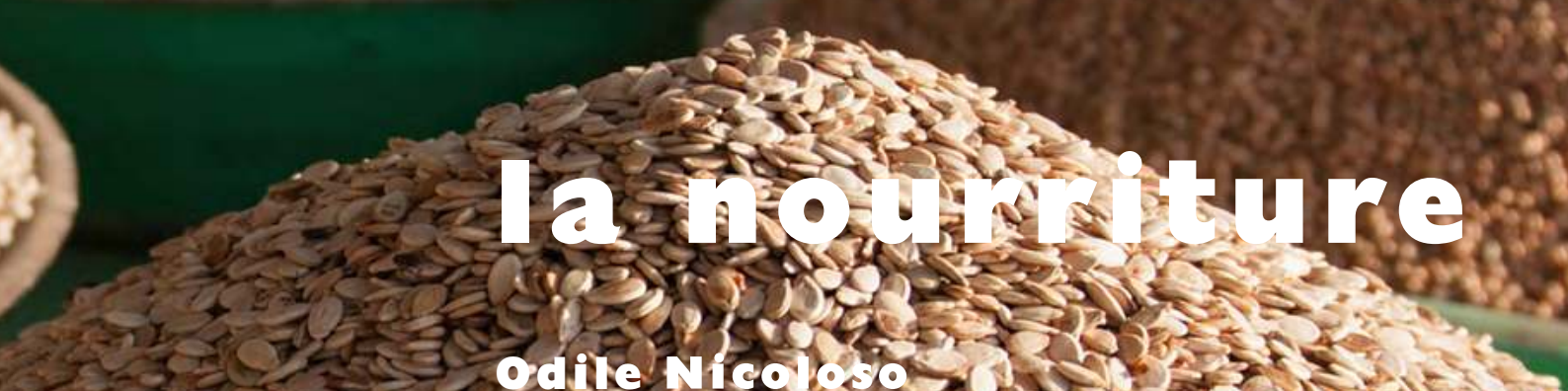

2tandinge

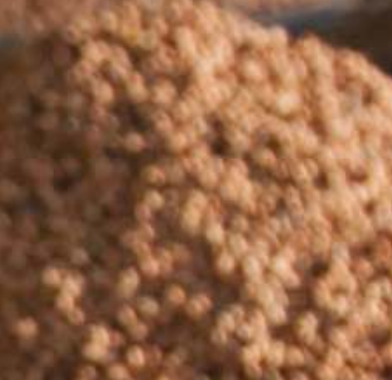

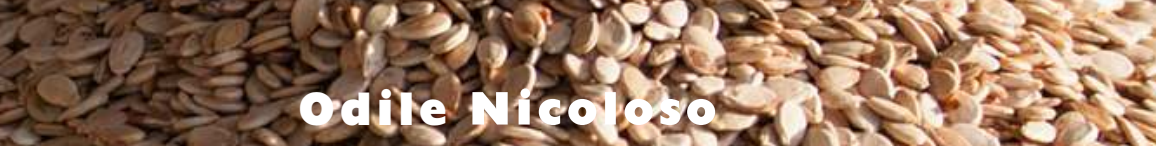

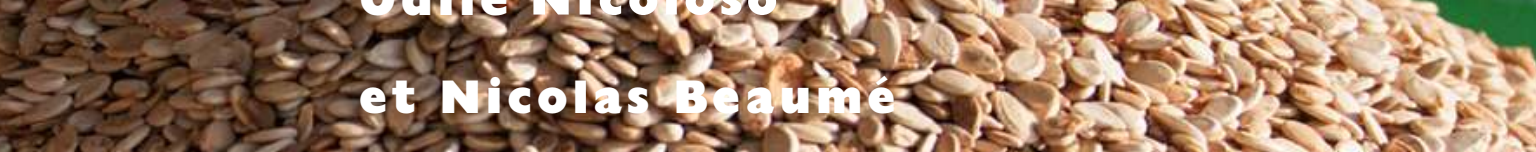

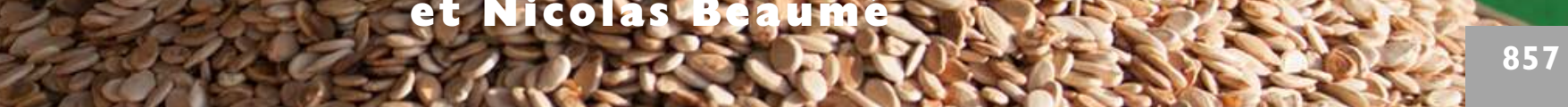

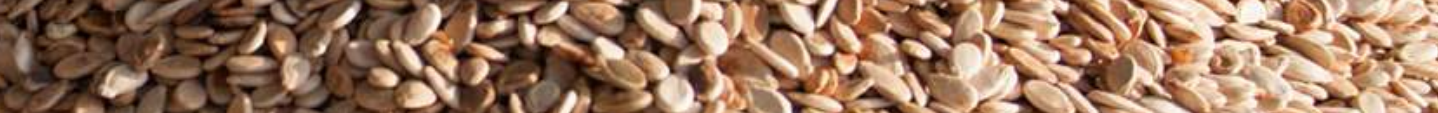

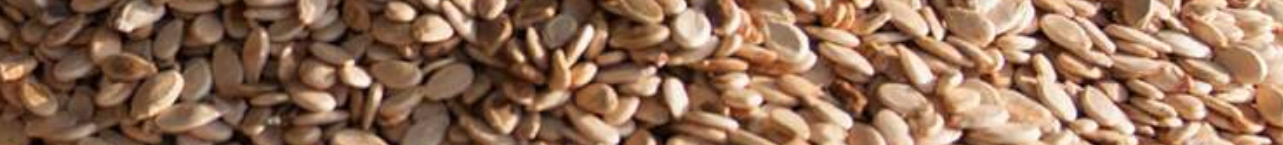
30
3

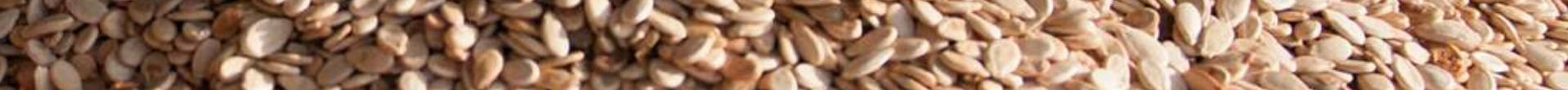

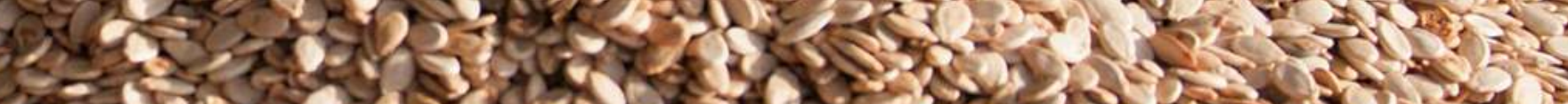
Les

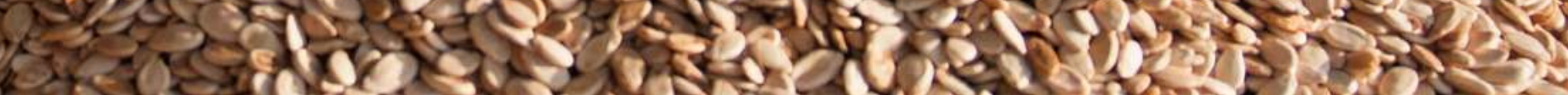

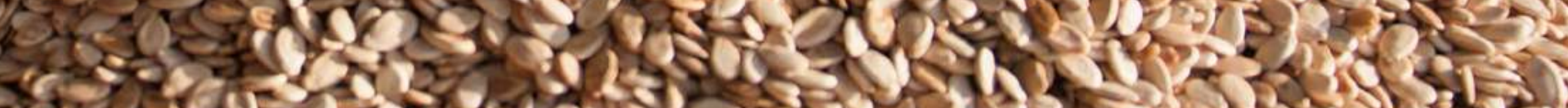
Vor

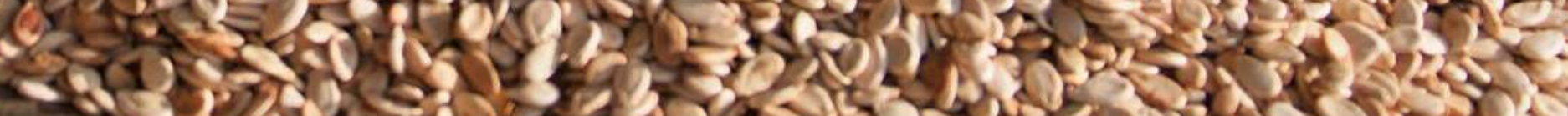

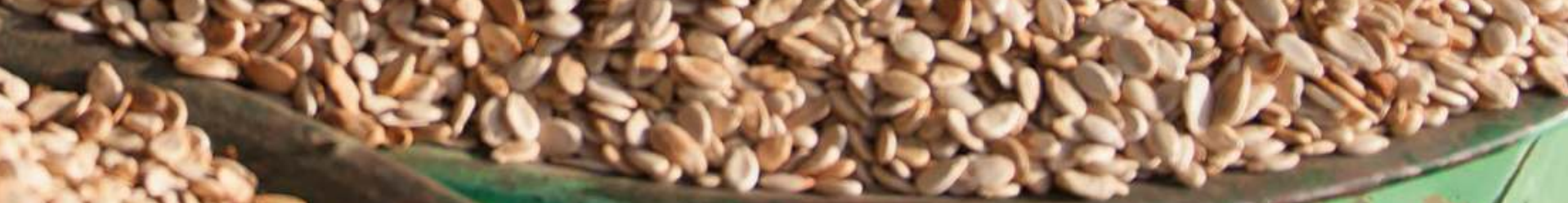

$$
x^{3}=72
$$



Les Soudanais prennent généralement trois repas par jour. Après un petit-déjeuner succinct, tôt le matin, qui souvent se limite à une tasse de café ou de thé, le premier vrai repas est le fatour, vers 11 heures. Il est composé essentiellement de foul, mets traditionnel à base de fèves mijotées auxquelles les Soudanais, suivant leurs moyens ajoutent oignons, œufs, viande, taamiya (falafel)...

Vers 15 heures a lieu le déjeuner: la famille se rassemble alors autour d'un plat de riz, de galettes de maïs (kisra), de pommes de terre, de viande, d'oignons et de tomates. La perche du Nil est un mets très prisé et délicieux qu'on peut acheter au marché d'Omduman, ainsi que d'autres poissons (poisson-chat, boulti) pêchés le matin même dans le fleuve. Vers 21 heures se prend le dîner. Les restaurants soudanais servent cette nourriture traditionnelle et de la viande, souvent sous forme de kebab ou shawarma.

\section{le karkadé}

Le thé rouge, plus connu sous le nom de karkadé, provient de l'hibiscus. C'est l'une des boissons préférées dans le pays. Cette plante, connue dans de nombreux pays d'Afrique, pousse essentiellement dans la région du Kordofan. Les pétales sont récoltés à la main chaque automne puis séchés au soleil. On les infuse et consomme la boisson froide ou chaude. Le karkadé est aussi utilisé en pharmacie pour faire baisser la tension artérielle et comme colorant dans les boissons et la nourriture. Le karkadé, qu'on trouve aussi communément en Égypte, est également la boisson nationale du Sénégal, du Burkina Faso et du nord du Bénin.

Élaboré avec le fruit du baobab, le tabaldi est la seconde boisson nationale du Soudan. On pourrait dire que dans le baobab tout est bon : son fruit est comestible et son goût acidulé plaît aussi bien aux humains qu'aux singes (d'où son appellation de "pain de singe"); il est très riche en vitamines B1 et $\mathrm{C}_{3}$ et contient deux fois plus de calcium que le lait. Ce fruit entre dans de nombreuses préparations: sa pulpe fraîche ou séchée, mêlée à de l'eau, fournit ainsi le tabaldi, une boisson rafraîchissante. Ses graines, consommées grillées, sont très nourrissantes et peuvent remplacer le café; on en extrait aussi une huile alimentaire. 


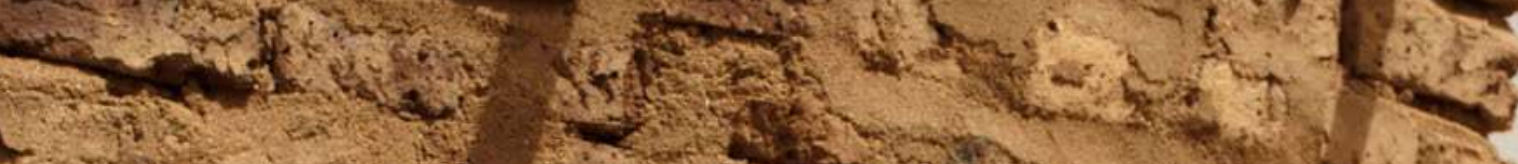

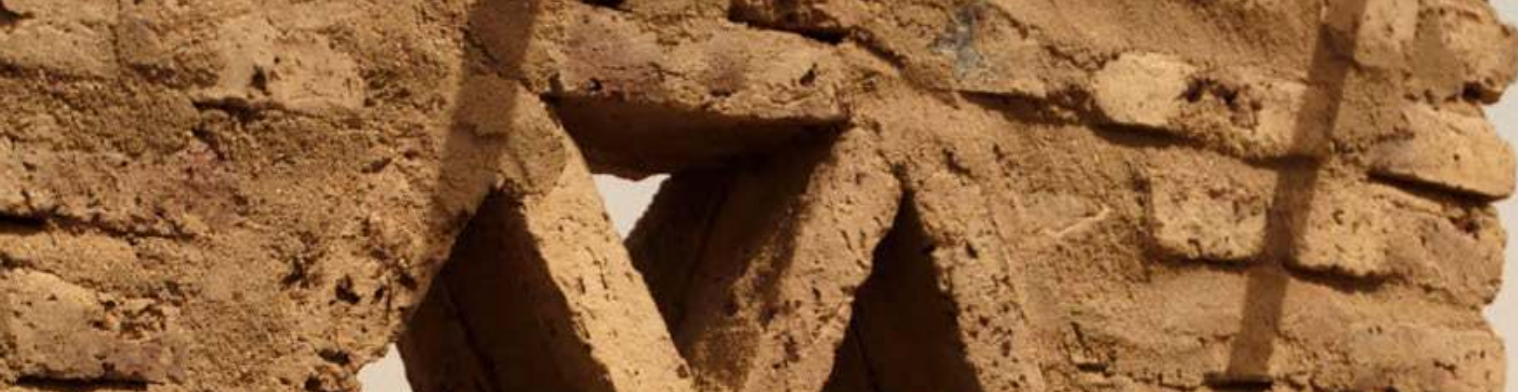
$\frac{1}{1}-2$ (2)

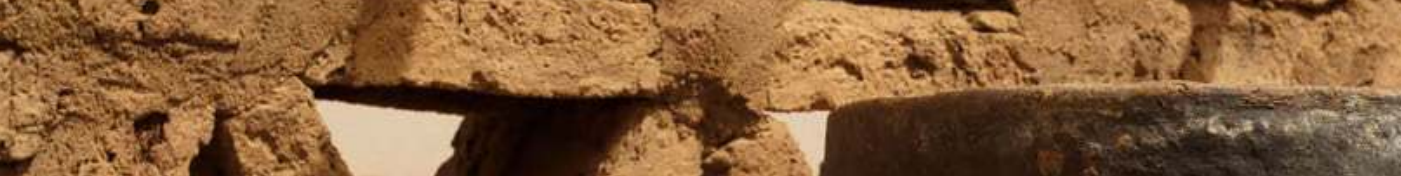
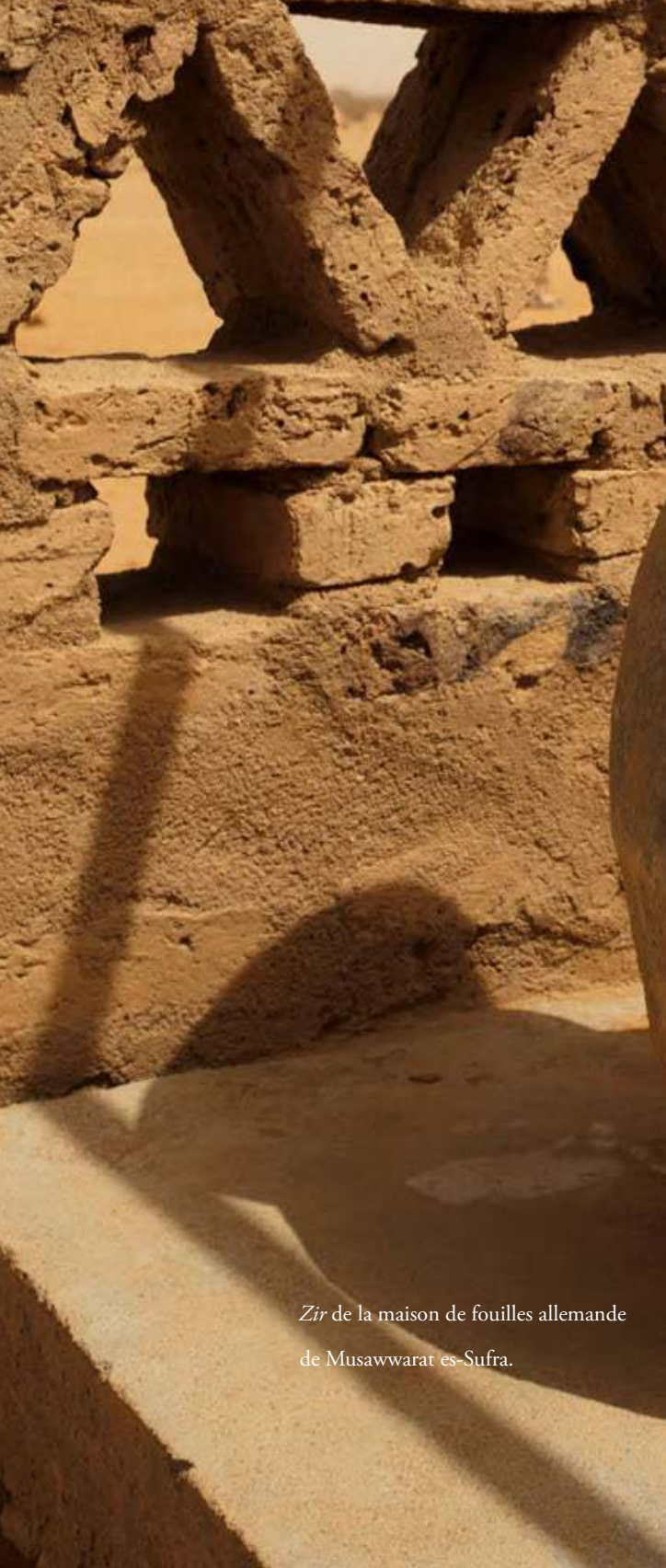

Zir de la maison de fouilles allemande

de Musawwarat es-Sufra.
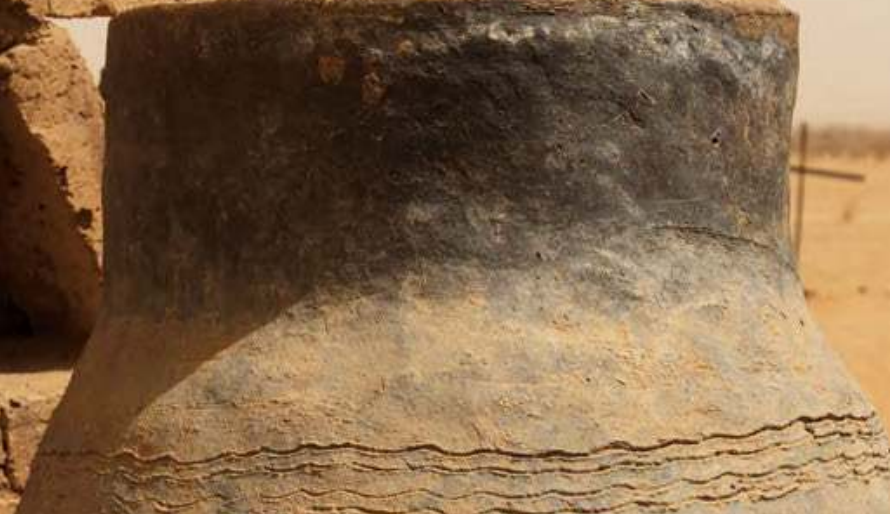
Le café soudanais ou jabana est pimenté suivant les goûts avec diverses épices: gingembre, cardamome, cannelle.

\section{le thé}

Boisson nationale par excellence, on le boit à toute heure de la journée: le matin, avec du lait, et dans la journée, épicé, au gingembre ou aux clous de girofle. Il est généralement très sucré. Toutes ces boissons peuvent se déguster du petit matin jusqu’à tard le soir chez les tea-ladies (voir p. 836-837).

Au bord des routes et à chaque coin de rue des villes du Soudan, à l'ombre, on trouve les zirs: grands pots de terre remplis d'eau qui, fermés et légèrement poreux pour permettre l'évaporation et garder la fraîcheur, sont à la disposition des passants; ils sont salvateurs dans ce pays si chaud où la température peut parfois avoisiner les $50{ }^{\circ} \mathrm{C}$.

L'alcool est en principe interdit. Certains s'en procurent au marché noir, d'autres en fabriquent clandestinement à partir de dattes ou de maïs. Il faut bien sûr se méfier des distillateurs sauvages et des alcools frelatés (les drames semblent fréquents). De dattes de différentes espèces, on tire une liqueur: l'araqi.

De nombreux fruits et légumes sont particulièrement délicieux, en particulier pastèques, citrons et les pamplemousses. Le foul sudani, ou cacahuètes, vendu au bord du trottoir par les femmes qui l'ont grillé au préalable, est employé également pour l'élaboration de sauces $\square$

Khartoum, souk aux antiquités et marché des peintres, 2012.
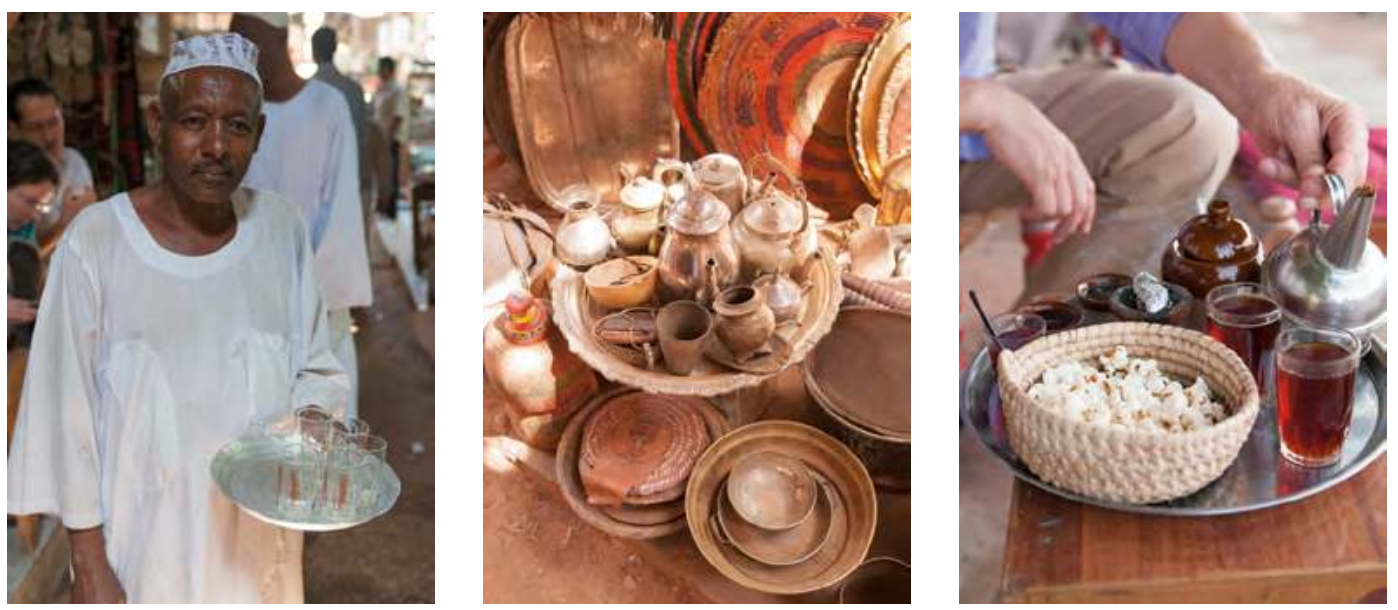


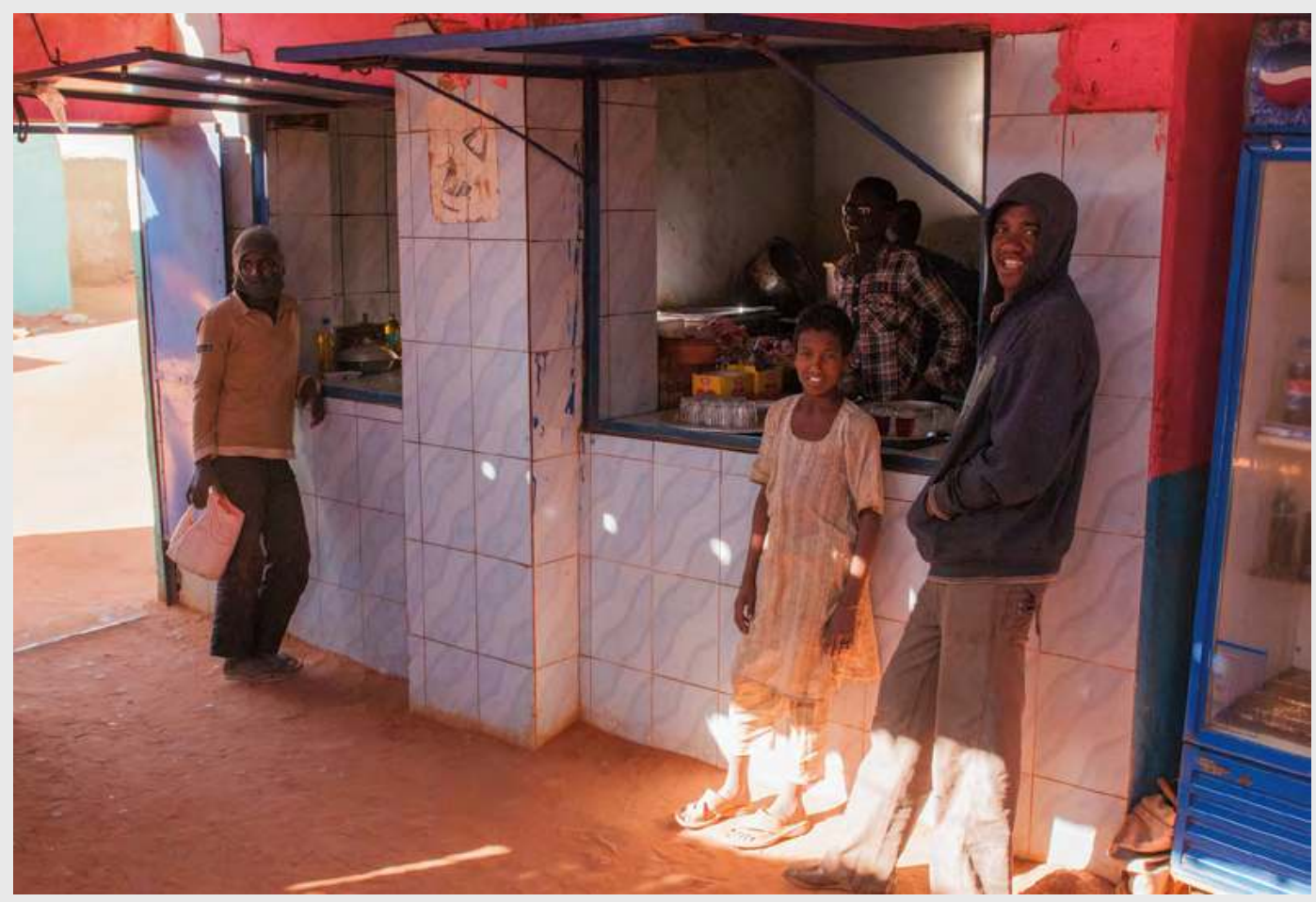

le Soudan

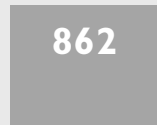

aujourd'hui
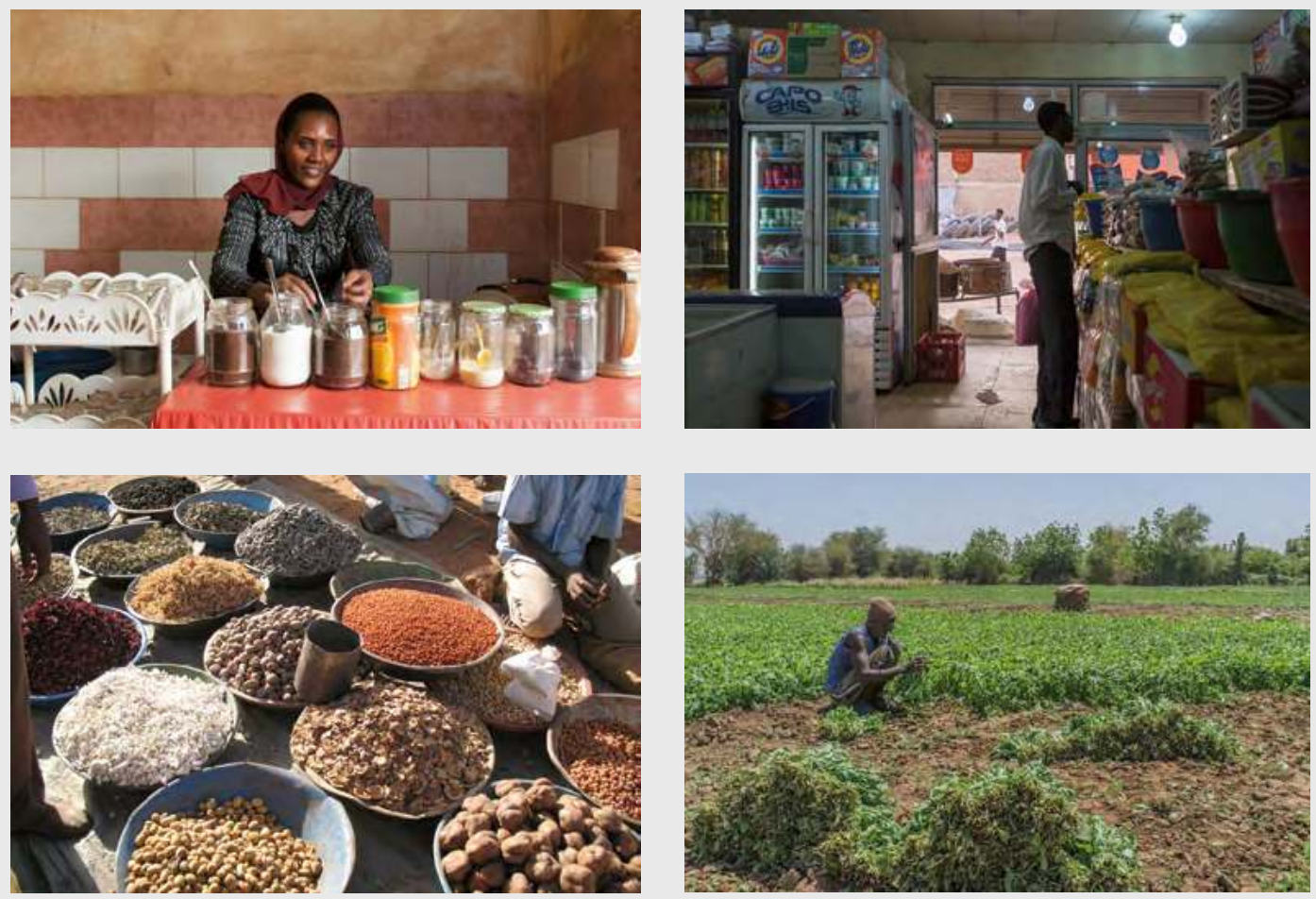

Restaurant, environs de Karima, 2012; île de Tuti, 2012; épicerie, Shendi, 2013;

étal, el-Obeïd, 2008; culture du gargir (sorte de roquette poivrée), île de Tuti, 2013. 

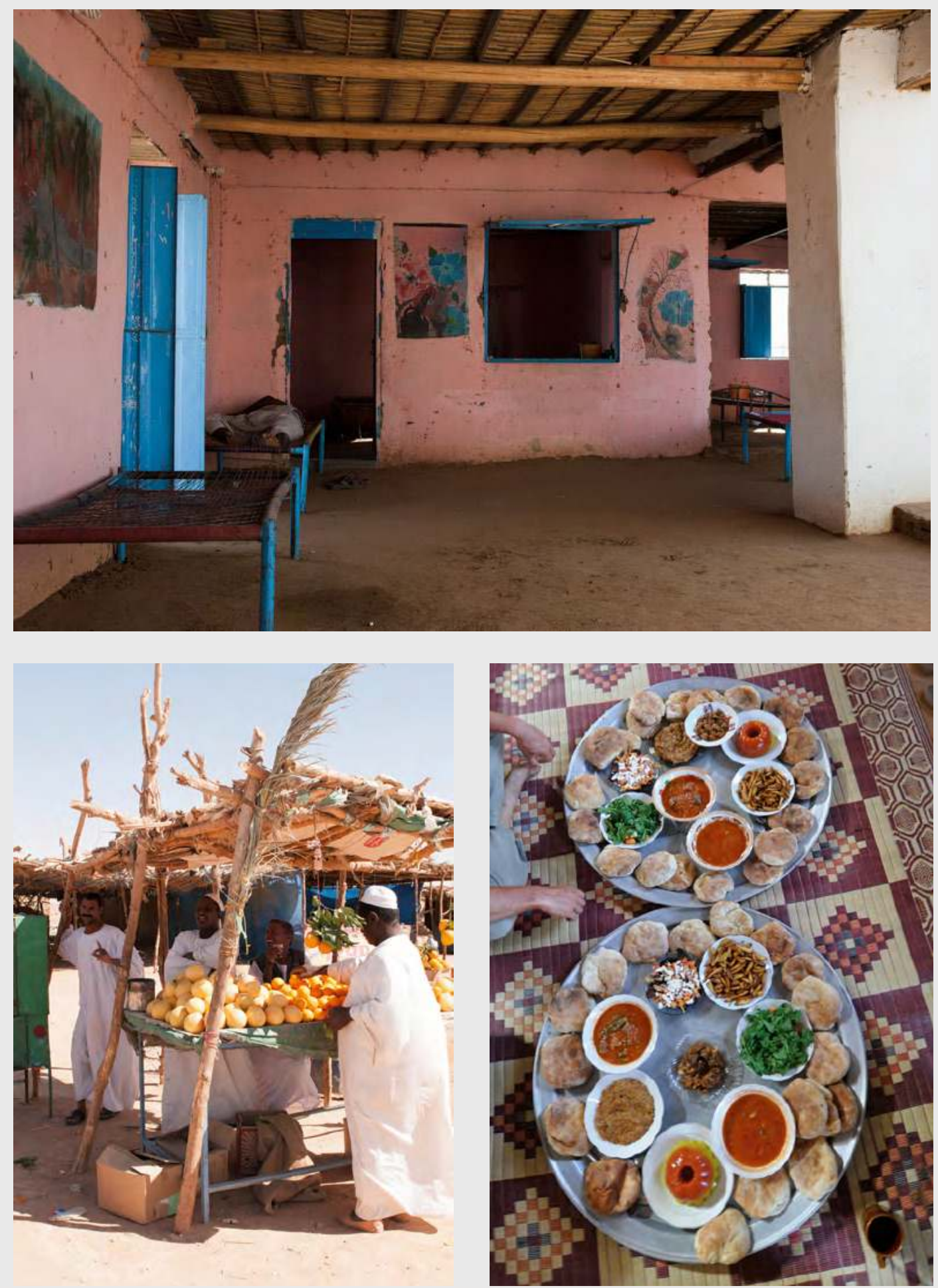

Relais « routier» aux environs de Méroé, 2011; marchand de fruits

aux environs d'el-Kourrou, 2013; repas de fête chez le raïs d'el-Hassa, 2010. 